J. Ginseng Res.

Vol. 33, No. 4, 343-348 (2009)

\author{
산처리 홍삼과 추출물의 특성 \\ 김미현 · 이영철 · 최상윤 · 조장원 · 노정해* \\ 한국식품연구원 \\ (2009년 10월 13일 접수; 2009년 12월 10일 수정; 2009년 12월 11일 수리)
}

\title{
Characteristics of Acid Pre-treated Red Ginseng and Its Decoction
}

\author{
Mi Hyun Kim, Young Chul Lee, Sang Yoon Choi, Chang-Won Cho and Jeonghae Rho* \\ Korea Food Research Institute, Seongnam, 463-746, Korea \\ (Received October 13, 2009; Revised December 10, 2009; Accepted December 11, 2009)
}

\begin{abstract}
This study was conducted to produce a new red ginseng by steaming ginseng using a new pre-treatment method, so as to develop ginseng products with improved flavor and thereby expand ginseng's consumer base. The color parameters (Hunter value), free sugar contents, and ginsenoside contents of the powder from the dried red ginseng, and the sensory test of the semi-dried red ginseng and the decoction from the dried red ginseng, were measured to investigate the effect of acid (ascorbic acid or citric acid) impregnation pre-treatment on red ginseng. The powder from the acid-pretreated red ginseng became lighter and more yellow than the red ginseng that was not pre-treated, but the redness (avalue) of the powder from the acid-pre-treated red ginseng increased. The ginsenoside contents of $\operatorname{Rg}_{2}+\mathrm{Rh}_{1}$ and $\mathrm{Rg}_{3}$ increased with the acid treatment. There was a significant difference in the color and sweetness of the semi-dried acidtreated and non-treated red ginsengs in the sensory test. As the results of the sensory test were expressed in the hedonic scale, however, there were significant differences in the degrees of bitterness, astringency, sourness, odor, and color of the red ginseng decollation. Especially, the acid-treated red ginseng extract tasted less bitter, which shows the potential of new red ginseng products with improved ginseng flavor.
\end{abstract}

Key words : acid, red ginseng, ascorbic acid, citric acid, ginsenoside

\section{서 론}

인삼은 식물 분류상으로 두릅나무 (Aealiaceae)의 인삼속 (Panax)에 속하며 주로 뿌리를 약재로 이용한다. Panax란 어 원은 희랍어로 Pan (all)과 Axos (cure)의 복합어로 만병을 치료한다는 뜻이다. ${ }^{1-3)}$ 인삼의 성분은 약 $60 \%$ 의 탄수화물, 8 $15 \%$ 의 조단백질, $1-3 \%$ 의 조지방, $4-6 \%$ 의 회분, $3-7 \%$ 의 조 사포닌, 그 외 미량성분들로 구성되어 있다.4)

우리 조상들은 '약식동원'이라 하여 약과 식품을 하나로 보 았으며, 여기서 생긴 것이 약선이라는 음식이이다. 약선 음식 이란 한의학 이론에 근거하여 약과 선은 근본적으로 같은 것 이라는 인식 아래 생약이나 그 밖에 약용가치가 높은 식품을 잘 배합하여 조리한 음식을 뜻한다. 예로부터 궁중뿐만 아니

*Corresponding author. E-mail: drno@kfri.re.kr Phone: +82-31-780-9060, Fax: +82-31-709-9876
라 민간에서도 천연 약재와 식품을 배합한 다양한 약선 비방 이 전해져 내려오고 있으며, 이러한 약선은 우리의 건강을 유 지시킬 뿐만 아니라 질병을 치료하는 효능도 가지고 있다. ${ }^{5,6)}$ 인삼은 다른 식품과 함께 조리하여도 잘 부합되므로 기능성 건강식품으로서의 가치는 매우 높다. 그리하여 인삼잼, 인삼 샐러드 드래싱, 인삼 과자 등으로 현대에 다양한 요리 방법으 로 연구되고 있는 있는 실정이다.7)

인삼 효능에 대해서는 예로부터 수 천년 동안의 경험에 의 하여 그 약효가 특출한 것으로 알려져 왔으며, 현대에 이르러 서는 세계 각국에서 활발한 과학적 연구가 진행되어 인삼의 효능이 생리학, 생화학, 약리학 및 병리학적인 지식에 바탕을 둔 임상학적인 연구결과가 보고되어 있다. ${ }^{8-10)}$ 인삼의 화학성 분과 약용성분인 사포닌 (ginsenoside)는 인삼속 식물에만 함 유된 dammarene 골격을 가진 triterpenoid 배당체로 지금 까지 약 40여종이 발견되고 있다. ${ }^{11)}$ Ginsenoside는 중추신경 
계를 비롯하여 내분비계, 면역계, 대사계 등에 광범위한 영향 을 미쳐 신체기능 조절, 즉 생리기능 정상화에 탁월한 효과를 나타내는 것으로 확인되고 있다. ${ }^{12,13)}$

지금까지 인삼에 대한 연구는 인삼의 성분과 약리 효과에 대한 연구가 주류를 이루어 왔고 이에 비하여 식품학적 연 구논문의 비율은 매우 낮아 식품학적 관점에서의 연구가 부 족한 실태임을 드러내고 있다. 또한 너무 깊이 인식되어온 인삼제품에 관한 고정관념으로 새로운 제품에 대한 개발이 늦춰져 왔다. 그러므로 향후 인삼의 맛, 향, 조직감 등을 고 려한 식품학적 관점에서 인삼을 가공하는 연구가 절실하다. 한국인의 인삼기호도 조사연구에 따르면 특히 젊은 세대로 내려 갈수록 인삼의 향취미에 관해서는 $25 \%$ 가 그저 그렇 다', $37 \%$ 가 ‘싫어한다'라고 나타나 인삼의 조리 방법과 제 품의 개발에 있어서 인삼의 향취미 개선이 절실함을 알 수 있다. ${ }^{14,15)}$

선행 연구에서 ascorbic acid, citric acid 등 유기산을 impregnation (감압침투)으로 유기산이 인삼에 침투하도록 시도 하였다. 그 결과, 유기산이 인삼에 침투하면 특정 ginsenoside $\mathrm{Rg}_{3}$ 가 강화되어 선택적 생리활성을 강화하거나 새로운 기능 성이 부여된 홍삼을 제조 할 수 있었다. 이에 본 연구에서는 새로운 전처리를 통한 홍삼을 제조하여 홍삼의 향취미의 변 화를 살펴보았고 이로써 맛과 향이 개선된 인삼제품을 개발 하고자 하였다.

\section{실험 재료 및 방법}

\section{재료}

시료는 안성인삼농협에서 2006년도 봄에 수확한 4-5근 수 삼을 대량 구매하여 $-2 \sim 0^{\circ} \mathrm{C}$ 에 보관하여 사용하였다. Ascorbic acid, citric acid는 특히 음료에 많이 사용되고 있 으며, $\mathrm{FDA}$ 에서 규정을 한 안전한 식품첨가물 이다. 수삼 내 부로 유기산이 침투되도록 하기 위한 산의 감압은 선행연구 를 통하여 얻어진 최적조건 (Table 1)에 따라 실시하여 산처 리 홍삼을 제조하였다.

\section{홍삼제조 방법}

유기산 감압 처리된 수삼은 Chang $\mathrm{JK}$ 등 ${ }^{16)}$ 방법을 사용하 여 홍삼을 사용하였다. 즉, 압력이 걸리지 않도록 $96 \sim 98^{\circ} \mathrm{C}$ 로 조정한 감압살균기 (MG-6845, Mega science, Seoul,
Korea)를 이용하여 2.5시간 증숙한 후 상온으로 냉각하고 $70^{\circ} \mathrm{C}$ 의 열풍 건조기 (WFO-601SD, Eyela, Tokyo, Japan) 에서 24 시간 건조한 홍삼을 반건조 홍삼으로 관능검사에서 사용하였다. 또한 반건조 홍삼을 $50^{\circ} \mathrm{C}$ 로 낮추어 약 72 시간 건조한 최종 홍삼을 색, 유리당, 추출물의 관능검사 시료로 이용하였다.

\section{산처리 홍삼의 색}

산처리한 홍삼을 분쇄기를 이용하여 60 mesh로 분쇄 한 후 색차계 (Chroma meter, CR 210, Minolta, Japan)를 사 용하여 밝기 (lightness)를 나타내는 L값, 적색도 (redness)를 나타내는 $\mathrm{a}$ 값, 황색도 (yellowness)를 나타내는 $\mathrm{b}$ 값을 각각 10 회 측정하였다. 이때의 표준판의 색은 $\mathrm{L}$ 값 97.69 , a값 $+0.37, \mathrm{~b}$ 값 +1.96 인 백색의 calibration plate를 표준으로 하여 측정하였으며, 사용된 산처리 홍삼의 양은 약 $50 \mathrm{~g}$ 을 이용하였다.

\section{Ginsenosides 함량측정}

조사포닌은 인삼분말 $1 \mathrm{mg}$ 당 들어있는 함량으로 환산하여 메탄올 $1 \mathrm{~mL}$ 에 녹여서 microfilter kit $(0.45 \mu \mathrm{m}$, Whatman $)$ 를 이용, 여과하여 vial에 담아 검액으로 사용하였다. 측정 방 법은 $\mathrm{HPLC}$ 를 이용하여 분석 기준물질 $\mathrm{Rg}_{1}, \mathrm{Re}, \mathrm{Rf}, \mathrm{Rb}_{1}$, $\mathrm{Rg}_{2}, \mathrm{Rh}_{1}, \mathrm{Rc}, \mathrm{Rb}_{2}, \mathrm{Rb}_{3}, \mathrm{Rd}, \mathrm{Rg}_{2}, \mathrm{Rh}_{2}$ 등의 12 가지 ginsenoside (Chengdu, PR China)를 각각 $0.1 \mathrm{mg} / \mathrm{mL}$ 농도 가 되게 하여 함량을 측정하였다. HPLC에 의한 ginsenoide 의 정량은 HPLC column : Waters $\mu$-Bondapak $\mathrm{C}_{18}$ 을 이 용하였고 이동상은 water (용매A)와 acetonitrile (용매B)를 초기에 용매 A $80 \%$ 에서 70 분 후 $0 \%$ 로 기울기용리 하였다. 용출 속도는 $1 \mathrm{~mL} / \mathrm{min}$ 였으며, 검출기는 $\mathrm{UV}$ detector (UV-2075 PLUS UV-vis, JASCO, Japan)을 사용하여 203 $\mathrm{nm}$ 에서 흡광도를 측정하였다. ${ }^{17-19)}$

\section{산처리 홍삼의 유리당 함량}

홍삼 분말 $5 \mathrm{~g}$ 을 $250 \mathrm{~mL}$ 공전 플라스크에 취하고 약 $50 \%$ 에탄올 용액 $100 \mathrm{~mL}$ 을 첨가하고 환류 냉각기에서 약 1 시간 추출하였다. 이 추출액을 $0.45 \mu \mathrm{m}$ 막필터로 여과한 것 을 시료로 HPLC를 분석하였다. HPLC에 의한 유리당 함량 은 Carbohydrate Column $(30 \times 300 \mathrm{~mm}$, Waters)을 이용하 였고 이동상은 $\mathrm{CH}_{3} \mathrm{CN}: \mathrm{H}_{2} \mathrm{O}(80: 20, \mathrm{v} / \mathrm{v})$ 를 사용하였다. 용출

Table 1. Processing conditions for acid impregnation pre-treated red ginseng

\begin{tabular}{cccc}
\hline \hline & Temperature $\left({ }^{\circ} \mathrm{C}\right)$ & Concentration $(\mathrm{M})$ & Time $(\mathrm{min})$ \\
\hline Ascorbic acid & 14 & 1.0 & 21.5 \\
Citric acid & 14 & 1.3 & 21.5 \\
\hline
\end{tabular}


속도는 $1 \mathrm{~mL} / \mathrm{min}$ 였으며, 검출기는 Refractive Index Detector (RI detector)을 이용하여 측정하였다.

\section{산처리 홍삼의 관능검사}

산처리 홍삼과 산처리 하지 않은 홍삼을 반 건조한 후 난 수표에 따라 3 자리 숫자로 시료 번호를 지정하고 흰 접시에 담아 제공 하였다. 관능적 특성 항목은 색 (color), 쓴맛 (bitterness), 단맛 (sweetness), 신맛 (sourness), 향취 (odor) 기호도를 조사하였다. 각 항목에 대한 기호도는 '매우 싫다'를 1점을 ‘아주 좋다’를 9점으로 표시하도록 하였으며, 분석 패널 은 25 50세의 다양한 연령으로 20 명을 선정하고 홍삼의 관능 적 특성에 대한 훈련을 시킨 후 관능검사를 실시하였다.

\section{산처리 홍삼의 추출물 관능검사}

산처리 건조 홍삼과 산을 처리하지 않은 건조 홍삼에 $200 \mathrm{~g}$ 증류수 $2 \mathrm{~L}$ 를 넣어 홍삼 추출물이 $200 \mathrm{~mL}$ 가 되도 록 약탕기 (DWP-5000M, 대웅 전자, Korea)를 이용하여 2 시간 30 분을 달인 후 난수표를 이용하여 시료번호를 정하고 종이컵에 담아 제공 하였다. 관능적 특성항목은 색 (color), 떫은맛 (astringency), 쓴맛 (bitterness), 단맛 (sweetness), 신맛 (sourness), 향취 (odor) 강도를 조사하였다. 각 항목에 대한 강도는 '매우 약하다'에 1점을 '매우 강하다'에 9점으로 표시하도록 하여 산처리 홍삼과 산을 처리하지 않은 홍삼 추 출물의 관능적 차이를 비교하였다.

\section{통계처리}

조사된 관능검사 결과는 SAS(Statistical Analysis System, 1996) 8.0 프로그램을 이용하여 ANOVA로 검증하였다.

\section{결과 및 고찰}

\section{산처리 홍삼의 색}

산을 처리하여 만든 홍삼 분말과 산을 처리 하지 않은 홍 삼 분말의 색을 비교한 결과는 Fig. 2 와 같이 나타났다. 밝 기 $(\mathrm{L})$ 는 산을 처리한 홍삼 값이 산을 처리하지 않은 홍삼 값 보다 낮은 값을 나타났으며, 황색도 (b)도 산을 처리한 홍삼에 서 낮은 값을 나타내었다. 그러나 적색도 (a)는 산을 처리한 홍삼 값이 산을 처리하지 않은 홍삼보다 높은 값을 나타났다. Ascorbic acid 처리한 홍삼의 경우 약 $30 \%$ 이상의 적색도가 증가 하는 것으로 나타났으며, 육안으로도 거의 검은 색에 가 까운 홍삼이 생산됨을 볼 수 있었다. Ascorbic acid 처리 홍 삼의 경우 색이 매우 진해지는데 이는 아마도 ascorbic acid 가 쉽게 산화되는 특성을 가지고 있는 것과 관련되는 것으로

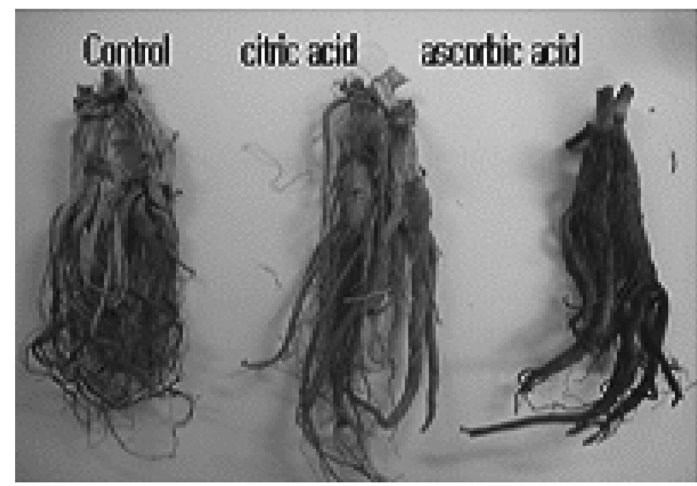

Fig. 1. Morphological properties of red ginseng pre-treated with acid impregnation.

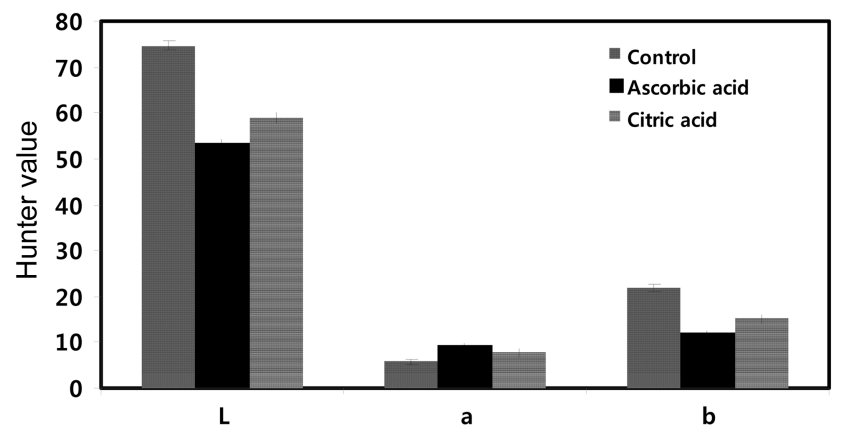

Fig. 2. Comparison of color of red ginseng pre-treatment with acid impregnation.

여겨지며 이러한 ascorbic acid의 autoxidation을 신속 흑삼 제조 등의 방법으로 이용한다면 매우 유용할 것이다. 흑삼의 경우 일부러 색을 검게 하기 위하여 overheat을 함으로써 유 해한 물질이 발생될 수 있는데 ascorbic acid 등을 통하여 전처리를 할 경우 이를 방지하면서도 색이 진하고 $\mathrm{Rg}_{3}$ 가 높 은 제품을 얻어낼 수 있을 것이다.

\section{Ginsenosides 함량측정}

전 처리한 산의 종류에 따라 ginsenoside pattern은 각각 다른 양상을 나타내었다. $\mathrm{Rg}_{3}$ 의 경우 ascorbic acid, citric acid 전처리에 의해서 모두 현격히 증가되었으며 특히 citric acid의 경우 $\mathrm{Rg}_{3}$ 강화가 수 십배에 이르렀다. $\mathrm{Rg}_{3}$ 는 항암, 혈액 순환기에 좋은 효과가 있는 것으로 알려져 있으므로 ascorbic acid, citric acid로 전처리한 홍삼은 항암 등에 효과 적일 수 있을 것으로 사료되었다. ${ }^{20)}$

$\mathrm{Rg}_{1}, \mathrm{Re}, \mathrm{Rc}, \mathrm{Rb}_{2}+\mathrm{Rb}_{3}$ 의 함량은 전처리하지 않은 홍삼에 비해 ascorbic acid, citric acid 처리한 홍삼에서 모두 감소 되는 것을 볼 수 있었으며, $\mathrm{Rg}_{2}+\mathrm{Rh}_{1}$ 의 함량은 ascorbic acid, citric acid 처리한 홍삼이 증가되는 것으로 나타났다. 
Table 2. Comparison of ginsenoside contents in red ginseng pre-treatment with acid impregnation (Unit: $\mathrm{mg} / \mathrm{g}$ )

\begin{tabular}{cccccccccc}
\hline \hline & $\mathrm{Rg}_{1}$ & $\mathrm{Re}$ & $\mathrm{Rf}$ & $\mathrm{Rg}_{2}+\mathrm{Rh}_{1}$ & $\mathrm{Rc}$ & $\mathrm{Rb}_{2}+\mathrm{Rb}_{3}$ & $\mathrm{Rd}$ & $\mathrm{Rg}_{3}$ & $\mathrm{Rb}$ \\
\hline Control & 0.99 & 1.27 & 0.63 & 0.35 & 1.83 & 1.10 & 0.89 & 0.22 & 0.62 \\
Ascorbic acid & 0.80 & 0.57 & 0.57 & 0.50 & 1.21 & 0.85 & 0.34 & 0.59 & 0.30 \\
Citric acid & 0.68 & 0.55 & 0.77 & 0.86 & 1.41 & 0.89 & 0.90 & 1.51 & 0.86 \\
\hline
\end{tabular}

\section{산처리 홍삼의 유리당 함량}

Ginsenoside는 당을 함유하고 있는 배당체이다. 당의 종류 와 그 위치에 따라 ginsenoside의 종류가 달라지며, 홍삼의 제조 과정에 의해 이 당은 유리되게 된다. 유리당 중 fructose는 산을 처리하지 않은 홍삼이 $1.75 \%$ 로 가장 높게 나타났으며, ascorbic acid 처리한 홍삼에서 0.88 , citric acid 처리한 홍삼에서 0.34 으로 나타났다. 또한 glucose도 비슷한 경향을 보였다. 그러나 sucrose의 경우 ascorbic acid처리한 홍삼이 9.17로 가장 높게 나타났으며 뒤이어 citric acid, 산 을 처리하지 않은 홍삼 순으로 나타났다. Maltose는 citric acid 처리한 홍삼은 산을 처리하지 않은 홍삼과 ascorbic acid 처리한 홍삼 보다 약 2 배 높게 나타나는 것을 볼 수 있었다.

인삼속 식물에는 triterpenoid계의 담마란계의 사포닌이 특이 적으로 존재한다. 4 환성의 담마란계 사포닌은 비 당부분에 붙어 있는 수산기 $(-\mathrm{OH})$ 수에 따라서 2 개인 경우 protopanaxadiol $(\mathrm{PD})$ 계로, 3 개의 경우 protopanaxatriol $(\mathrm{PT})$ 계로 사포닌으로 구별된다. ${ }^{21)}$ 산을 처리하여 증가된 protopanaxatriol 계통인 $\mathrm{Rg}_{2}$ 은 $\mathrm{Re}$ 의 20 번 $\mathrm{OH}$ 자리에 glucose가 있는 ginsenoside로서 이 glucose가 ascorbic acid에 의하여 탈락되므로 $\mathrm{Rg}_{2}$ 가 생 성되게 된다. 또한 protopanaxadiol 계통의 $\mathrm{Rg}_{3}$ 는 $\mathrm{Rb}_{1}, \mathrm{Rb}_{2}$ 에서 20 번째 자리의 $\mathrm{OH}$ 위치에서 두 개의 당이 탈락되면서 생성된다. 즉 $\mathrm{Rb}_{1}$ 으로부터 glucose- glucose 가 탈락되고 $\mathrm{Rb}_{2}$ 으로부터 arabinose- glucose가 탈락되어 $\mathrm{Rg}_{3}$ 가 생성된다. 산 을 처리하면서 생성된 glucose는 인삼 속에 있는 fructose와 결합하여 sucrose의 함량이 증가되는 것으로 사료된다. ${ }^{22,23)}$

\section{산처리 홍삼의 관능검사}

반 건조 산처리 홍삼과 산을 처리하지 않은 반 건조 홍삼 을 색, 쓴맛, 단맛, 신맛, 향취를 측정한 결과는 Table 3 에

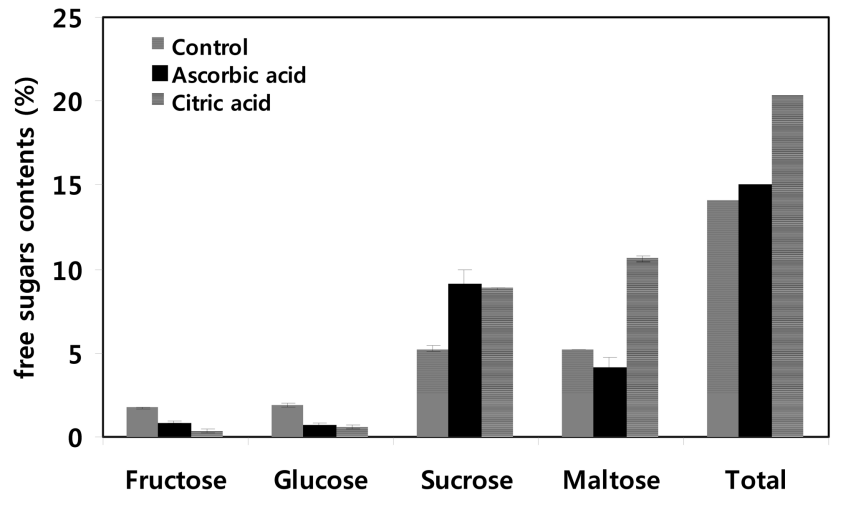

Fig. 3. Comparison of free sugars contents in red ginseng pretreatment with acid impregnation.

나타내었다. 홍삼의 색을 보면 일반 홍삼이 6.8 , citric acid 처리한 홍삼이 6.4 로 유의적인 차이는 나타나지 않았으나 ascorbic acid 처리한 홍삼은 4.8 로 유의적인 차이가 나타났 다 $(\mathrm{p}<0.0002)$. 이는 기기적으로 색을 측정한 $\mathrm{L}, \mathrm{a}, \mathrm{b}$ 의 결 과와도 부합되는 것이다. 한편 쓴맛에 있어서 일반홍삼은 6.4 였으나, ascorbic acid 처리한 홍삼은 5.4, citric acid 처리한 홍삼은 5.1 로 일반 홍삼에 비해 쓴맛이 적은 것으로 나타났 으나 유의적인 차이는 나타나지 않았다. 신맛을 비교한 결과 는 ascorbic acid 처리한 홍삼이 5.4로 높았으며 일반홍삼이 5.2, citric acid는 4.7 순으로 평가되었으나 유의적 차이는 없 는 것으로 나타났다. 홍삼의 $\mathrm{pH}$ 가 일반 홍삼의 경우 5.27 이 었고 citric acid 처리 홍삼의 경우 3.6 였던 점을 고려하여보 면 기대하지 않았던 결과이었다. 이는 산을 처리하면서 홍삼 의 단맛을 감소시키나 산을 첨가하여도 홍삼의 신맛은 거의 변화가 없다는 의미이다. 단맛에 있어서는 일반 홍삼이 6.0 으 로 가장 좋았으며 ascorbic acid 처리한 홍삼이 5.4, citric

Table 3. Comparison of semi-dried red ginseng with acid pre-treatment to semi-dried red ginseng without pre-treatment in sensory test using hedonic scale

\begin{tabular}{ccccc}
\hline \hline & Control & Ascorbic acid & Citric acid & Pr $>|t|$ \\
\hline Color & $6.8 \pm 1.3^{\mathrm{a} \mid 2)}$ & $4.8 \pm 1.7^{\mathrm{b}}$ & $6.4 \pm 1.2^{\mathrm{a}}$ & 0.0002 \\
Bitterness & $6.4 \pm 1.4$ & $5.4 \pm 1.9$ & $5.1 \pm 2.0$ & 0.0594 \\
Sweetness & $6.0 \pm 1.6^{\mathrm{a}}$ & $5.4 \pm 1.7^{\mathrm{ab}}$ & $4.4 \pm 1.8^{\mathrm{b}}$ & 0.0230 \\
Sourness & $5.2 \pm 1.8$ & $5.4 \pm 1.6$ & $4.7 \pm 1.8$ & 0.4588 \\
Odor & $5.8 \pm 1.5$ & $5.8 \pm 1.8$ & $5.9 \pm 1.6$ & 0.9382 \\
\hline
\end{tabular}

\footnotetext{
${ }^{1)}$ Mean \pm SD

${ }^{2) a-b}$ Mean with different superscript in same row are significantly different $(p<0.05)$ by Duncan's multiple rage test
} 
Table 4. Comparison of the decoction from dried red ginseng with acid pre-treatment to the decoction from dried red ginseng without pre-treatment in sensory test using hedonic scale

\begin{tabular}{ccccc}
\hline \hline & Control & Ascorbic acid & Citric acid & Pr>|t $\mid$ \\
\hline Color & $5.3 \pm 1.1^{\mathrm{b} 1) 2)}$ & $7.5 \pm 0.8^{\mathrm{a}}$ & $4.3 \pm 1.2^{\mathrm{c}}$ & 0.0001 \\
Bitterness & $6.4 \pm 1.5^{\mathrm{a}}$ & $5.8 \pm 1.6^{\mathrm{a}}$ & $3.8 \pm 2.0^{\mathrm{b}}$ & 0.0010 \\
Astringency & $5.1 \pm 1.8^{\mathrm{a}}$ & $4.6 \pm 1.9^{\mathrm{a}}$ & $3.4 \pm 1.5^{\mathrm{b}}$ & 0.0047 \\
Sweetness & $4.7 \pm 2.1$ & $3.6 \pm 1.7$ & $3.6 \pm 1.9$ & 0.1023 \\
Sourness & $3.7 \pm 1.5^{\mathrm{b}}$ & $4.5 \pm 1.8^{\mathrm{b}}$ & $8.3 \pm 0.6^{\mathrm{a}}$ & 0.0001 \\
Odor & $5.7 \pm 1.9^{\mathrm{a}}$ & $6.5 \pm 1.0^{\mathrm{a}}$ & $3.6 \pm 1.5^{\mathrm{b}}$ & 0.0001 \\
\hline
\end{tabular}

${ }^{1)} \mathrm{Mean} \pm \mathrm{SD}$

${ }^{2) \mathrm{a}-\mathrm{b}}$ Mean with different superscript in same row are significantly different $(p<0.05)$ by Duncan's multiple rage test

acid 처리한 홍삼 4.4로 유의적 차이가 나타났다 $(\mathrm{p}<0.0230)$. 단맛에 영향을 줄 것으로 고려되는 인자는 유리당 함량이다. 총유리당 함량을 보면 오히려 citric acid가 가장 높았었다. 그러나 일반 홍삼의 경우 당 중에서도 단맛에 가장 중요한 요인으로 생각 되어지는 fructose 함량이 높았었다. 이러한 영향으로 일반홍삼의 단맛이 오히려 높은 것이 아닐까 사료 되었다. 또한 향취에서는 일반홍삼이 5.8 , ascorbic acid 처리 한 홍삼이 5.8, citric acid 처리한 홍삼이 5.9 로 유의적 차이 가 나지 않는 것으로 나타났다.

\section{산처리 홍삼의 추출물 관능검사}

건조된 산처리 홍삼과 산을 처리하지 않은 홍삼을 물로 추 출한 후 쓴맛, 떫은 맛, 단맛, 신맛, 향취, 색의 강도를 측정 하였는데 매우 강하는 9점을 매우 약하면 1점을 주었다. 홍 삼 추출물의 색은 ascorbic acid한 홍삼 추출물이 7.5로 가장 강한 것으로 나타났으며, 일반 홍삼 추출물 5.3 , citric acid 처리한 홍삼 추출물 4.3 순으로 나타났다. 쓴맛에서는 일반 홍삼 추출물 6.4 , ascorbic acid한 홍삼 추출물 5.8 로 유의적 차이가 나타나지 않았으나 citric acid 처리한 홍삼 추출물에 서는 3.8 로 쓴맛이 약해지는 것을 볼 수 있었다 $(\mathrm{p}<0.001)$. 떫은맛도 쓴맛과 유사한 결과를 보였는데 citric acid 처리한 홍삼 추출물이 3.4로 떫은맛이 가장 약한 것으로 나타났다. 단맛의 경우 일반 홍삼 추출물과 산을 처리한 홍삼 추출물 간에 유의적 차이가 나지 않았다. 신맛의 경우 일반 홍삼 추 출물은 3.7, ascorbic acid한 홍삼 추출물가 4.5로 유의적 차 이가 나지 않는 것에 비해 citric acid 처리한 홍삼 추출물에 서 신맛이 강하게 나타나는 것으로 나타났다. 이러한 결과는 $\mathrm{Rg}_{3}$ 강화 반 건조 홍삼의 관능 평가와는 상이한데 이는 홍삼 의 수분이 건조되고 또한 물에 달여지는 과정에서 산의 $\mathrm{pH}$ 가 달라져서 나타나는 현상으로 사료된다. 또한 향취에도 신 맛과 비슷한 결과를 나타났는데 이는 citric acid 처리한 홍삼 추출물은 신맛이 너무 강하여 쓴맛과 떫은맛을 감소시키고 추 출물의 향취도 감소되는 것으로 사료된다.

\section{요 약}

본 연구에서는 새로운 전처리를 통한 홍삼을 제조하여 홍 삼의 향취미의 변화를 살펴보았으며 이로써 맛과 향이 개선 된 홍삼제품을 개발하고자 하였다. Acid(ascorbic acid, citric acid) 감압침투 방법으로 산처리 홍삼을 제조하였으며, 반 건 조 산처리 홍삼과 반건조 홍삼의 색, 유리당, ginsenoside 함 량, 관능검사를 실시하였다. 홍삼분말 색은 산을 처리하면 밝 기 $(\mathrm{L})$ 와 황색도 $(\mathrm{b})$ 도는 감소하며, 적색도 $(\mathrm{a})$ 는 증가하는 것 으로 나타났다. Fructose, glucose는 산을 처리하지 않은 홍 삼이 가장 높았으나 sucrose, maltose는 citric acid 처리한 홍삼이 높게 나타나는 것을 알 수 있었다. Ginsenoside 함량 은 산을 처리한 홍삼에서 $\mathrm{Rg}_{2}+\mathrm{Rh}_{1}, \mathrm{Rg}_{3}$ 의 함량이 증가 되 는 것을 알 수 있었다. 산을 처리한 반건조 홍삼과 일반 반 건조 홍삼 관능검사에서는 색과 단맛에서만 유의적 차이가 나 타났다. 그러나 건조 홍삼 추출물을 관능 검사한 결과 쓴맛과 떫은맛, 신맛, 향취, 색의 강도에서는 유의적 차이가 나타났 다. 특히 산 처리한 홍삼 추출물은 쓴맛과 떫은맛이 감소되어 산으로 전 처리한 홍삼은 인삼에 대한 거부감을 줄일 수 있 는 제품으로 사용 가능성을 보여 주었다.

\section{인용문헌}

1. Park JD. Recent studies on the chemical constituents of Korean Ginseng (Panax ginseng C. A. Meyer). Kor J Ginseng Sci. 20: 389-415 (1996)

2. Nam KY. The comparative understanding between red ginseng and white ginsengs processed ginsengs (Panax ginseng C. A. Meyer). Kor J Ginseng Res. 29: 1-18 (2005)

3. Choi KJ. The constituent of material ginseng and management of quality. Kor J Ginseng Sci. 15: 247-256 (1991)

4. Kong BM, Park MJ, Min JW, Kim SH, Kim SY, Yang DC. Physico-chemical characteristics of white, fermented and red ginseng extracts. Kor J Ginseng Res. 32(3): 238-243 
(2008)

5. Cho YY, Cho KH. Medinal foods eating by color. Gwangmoongak Seoul. p 4-5 (2005)

6. Paek JK, Kim JH, Yoon SJ. Quality characteristics of ginseng Junh Kwa affer diifferent soaking times in sugar syrup. Kor J Food Cookery Sic. 22: 792-798 (2006)

7. Park SH. Ginseng culinary cuisine for medicine, Korea Culinary Cuisine Information Ltd. Seoul. p 120-135 (2003)

8. Ando T, Tanaka O,Shibata S. Comparative studies on the saponins and sapogenins of ginseng and related crude drugs. Syoyakugaku Zasshi. 25: 28-32 (1971)

9. Yamaoto H, Kutano M, Matsunaga H. Ant-tumor substance from Panax ginseng roots. Kor J Ginseng Sci. 14: 244-252 (1990)

10. Yokozawa T, Oura H, Kawashima Y. Effect of administration of ginsenoside- $\mathrm{Rb}_{2}$ in diabetic rats: In terms of carbohydrate and lipid metabolites. Chem Pharm Bull 35: 4872-4877 (1987)

11. Shiabta S. Studies on constituents of Japanese and Chinese crude drugs XI. Panaxadola sapogenin of ginseng roots(1). Chem Pharm Bull. 11: 59-76 (1973)

12. Hwang YK, Lee SD. Inhibitory activity of acidic polysaccharide of Korean red ginseng on lipolytic action of toxohormone-L from cancerous ascites fluid. Kor J Food Nutr. 5: 7-12 (1992)

13. Lee SD, Hawang YK. Effect of Korean red ginseng component on lipolytic action of toxohormone-L from cancerous ascites fluid. Kor J Food Sci Nutr. 8: 105-109 (1995)

14. Hyun SS, Jae WY, Byeong SJ, Na MK, Yoon DK. A study on preference for ginseng in Korean $\Pi$ The college student's viewpoint. Kor J Ginseng Sci. 13(1): 130-135 (1989)
15. Keum YS, Park KK, Lee JM, Chun KS, Park JH, Lee SK, Kwon H, Surh YJ. Antioxidant and anti-tumor promoting activities of the methanol extract of heat-processed ginseng. Caner Lett. 150: 41-48 (2000)

16. Chang JK, Park CK, Shim KH. Changes in chemical components of red ginseng processed from the fresh ginsengstored at low temperature. Kor J Food Preservation 10: 158161 (2003)

17. Hong HD, Sim EM, Kim K, Rho J, Rhee YK, Cho CW. Comparison of preparation methods for the quantification of ginsenosides in raw Korean ginseng. Food Sci Biotechnol. 18: 565-569 (2009)

18. Hong HD, Choi SY, Kim YC, Lee YC, Cho CW. Rapid determination of ginsenosides $\mathrm{Rb}_{1}, \mathrm{Rf}$, and $\mathrm{Rg}_{1}$ in korean ginseng using HPLC. J Ginseng Res. 33: 8-12 (2009)

19. Han CK, Hong HD, Kim YC, Kim SS, Shim GS. Effect of puffing on quality characteristics of red ginseng tail root. J Ginseng Res. 31(3): 147-153 (2007)

20. Han BH, Park MH, Han YN. Degradation of ginseng under mild acidic condition. Planta Med. 44: 146-149 (1982)

21. Horhammer L, Wagner H. Lay B Zur Kenntnis der Inhartsstofferon radix Panax ginseng C.A. Meyer Pharm Ztg. 106: 1307-1311 (1961)

22. Jeong SI, Lee TG, Kim CS, Lee S. Property and inhibition of hydrolysis of ginseng saponins by organic acids neutralization in ginseng extract preparation. Kor J Med Corp Sci. 6: 305-310 (1998)

23. Kong YH, Rho JH, Cho CW, Kim MH, Lee YC, Kim SS, Lee PJ, Choi SY. Variation of phenolic ingredient and ginsenoside content in red ginseng extract by acid treatment. J Ginseng Res. 33: 194-198 (2009) 